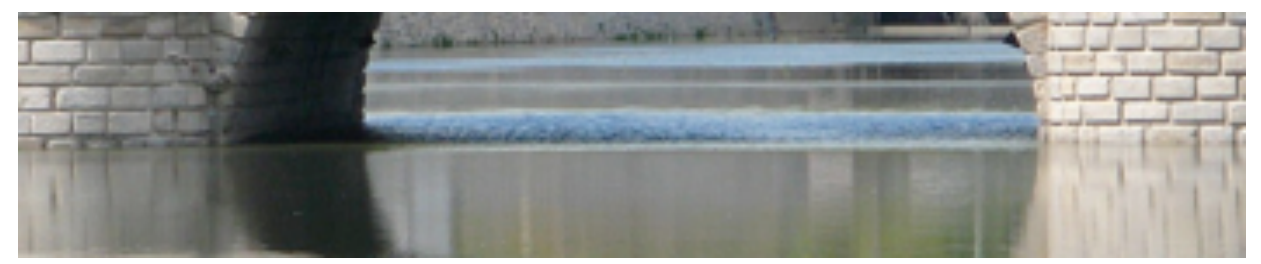

\title{
El sujeto móvil de la aldea global. Tendencias en la sociedad mediatizada
}

\section{The Mobile Subjet of the Global Village. Trends in Mediatized Society}

\author{
Eduardo Andrés Vizer ${ }^{(*)}$ \\ Universidade Federal da Integraçao Latinoamericana - Brasil \\ Universidad de Buenos Aires - Argentina \\ eavizer@gmail.com
}

\begin{abstract}
Resumen
El texto que aquí se presenta se inscribe en el contexto de la publicación: En las últimas décadas del siglo XX las TIC demostraron la capacidad de convergencia que les permite expandir exponencialmente no sólo múltiples usos diferentes, sino la posibilidad de creación y acceso universal a redes de información $y$ de comunicación. Ta en la primera década del siglo XXI el celular personal $y$ el desarrollo de aplicativos entre redes $y$ dispositivos de infocomunicación (presentando un cuadro más asimilable a una Sociedad de la Comunicación que de la Información) reinstala al individuo como un agente activo de convergencia entre múltiples sistemas de comunicación. Si el modelo de ser humano en la cultura letrada de la Modernidad era el sujeto lector reflexivo, en la presente modernidad tardía (postmodernidad?)
\end{abstract}

\begin{abstract}
In the last decades of the 20th century, ICT's showed their capacity for convergence, which permits them to expand not only multiple uses, but the possibility to create and promote universal access to information and communication networks. In the first decade of the 21st century, personal cell phones and applicative devices between networks and infocommunication devices (a picture which resembles more to a Communication Society than an Information one) reinstalls the individual as an active agent of convergence between multiple communication systems. If the model of a literate Modernity individual was that of a reflexive subject - a reader-, in present late modernity (postmodernity?) the new model is that of the mobile and itinerant subject of the globalized (and deterritorialized) village. Advances in
\end{abstract}


el nuevo modelo vigente es el sujeto móvil e itinerante de la nueva aldea globalizada (y desterritorializada). Los avances en la autonomía espacial y temporal de los individuos generan las condiciones para la expansión del acceso a la información y la comunicación, fortaleciendo los procesos de libre expresión más allá de la concepción conservadora que la reserva para los medios masivos.

Palabras clave: móvil, aldea global, tendencias, mediatización social, TIC. spatial and temporal autonomy of individuals generate conditions for the expansion in the access of information and communication, strengthening free expression further from the conservative conception which restrains it to media.

Keywords: mobile subject, global village, trends, social mediatisation, ICT's. 


\section{TeCNOLOGÍAS DE INFORMaCión Y COMUNiCACión Y NUEVAS PRÁCTICAS SOCIALES}

En buena medida, el paradigma emergente en el siglo XXI va demarcando nuevos modos de relación entre los individuos y las tecnologías de información y de comunicación, nuevas formas de expresión y participación social, y nuevas formas de apropiación del tiempo y del espacio. Las tendencias a la convergencia entre diferentes tecnologías ha dado lugar a una creciente mediatización de toda forma de prácticas sociales. Todas presentan en mayor o menor grado mudanzas al parecer definitivas, tanto cuantitativa como cualitativamente, a pesar de la fugacidad y la velocidad de suplantación de algunos dispositivos técnicos por otros, de algunas formas organizativas - y empresarias - del mundo digital por otras (Google, web 2, nuevos aplicativos, desarrollo de la telefonía celular, etc.). Según declaraciones de su creador, Facebook se propone como objetivo último mediatizar todas las relaciones sociales a través de una plataforma universal a fin de cubrir con redes virtuales todos los posibles escenarios mundiales.

En cuanto a diferentes formas de prácticas sociales neopolíticas, la figura del nuevo militante del siglo XXI puede presentarse ya no forzosamente como miembro de una organización social, sino como un individuo relativamente aislado pero con capacidad de acceso a una batería de medios: páginas web, blogs, e-mail, y la emergente explosión de la comunicación por telefonía móvil. El activismo social ya no es forzosamente organizado, ni requiere de actos de fe, formalidades ni rituales. Puede ser espontáneo, y tomar la forma de multitudes convocadas por situaciones críticas (como las manifestaciones policlasistas y con intereses diversos en la crisis de diciembre del 2001 en Argentina).

En marzo del 2004, casi sobre el día de las elecciones un terrible atentado planteó un difícil dilema al partido gobernante en España, el que controlaba la televisión pública y gran parte de la privada, así como la mayoría de las radios, contando con buena parte de la opinión pública a su favor. Los ciudadanos que no aceptaban las declaraciones iniciales del partido dirigente, -que atribuía a ETA la autoría del atentado- recurrieron a Internet y a los celulares para emprender movilizaciones espontáneas. Las manifestaciones no fueron mera consecuencia de los mensajes de correo electrónico y SMS (mensajes de texto). Quienes tenían motivos para actuar encontraron un nuevo medio para recabar información, publicar mensajes, 
organizar y generar manifestaciones. A través de los celulares los SMS se encargaron de poner en evidencia pública la manipulación y la desinformación instrumentados por el gobierno. Este no solamente perdió las elecciones, sino que indignó a la sociedad porque además de la tragedia y el terror del atentado, se sintió usada y engañada con fines electorales. Con las movilizaciones, se evaporó buena parte del capital de credibilidad en los medios de información masivos. Podemos decir que nos hallamos ante un nuevo medio de promover acontecimientos, aunque aún no se traduzcan abiertamente en formas permanentes de organización social, cultural y políticas.

"Con toda probabilidad no serán pacíficas o democráticas todas las movilizaciones futuras organizadas por Internet y el teléfono móvil. El motivo de esperanza mas pragmático es que el nuevo régimen tecnosocial es todavía joven” (Rheingold, 2004).

Las redes telefónicas inalámbricas y los sistemas informáticos accesibles a cualquier usuario, constituyen junto con la acción de individuos o grupos, un potencial de acción y de influencia inmenso, comparables seguramente al impacto histórico de la revolución de la imprenta o la creación del alfabeto. A través de las TIC, la oralidad recupera nuevamente un rol fundamental en la constitución de procesos sociales, sin desplazar la escritura, sino convergiendo con ella en nuevas formas de escrituras audiovisuales.

El proceso de "apropiación tecnosocial" de los espacios de comunicación sigue una tendencia de crecimiento exponencial. Si en el año 2004 se vendieron en el mundo 600 millones de teléfonos celulares, la décima parte de la población mundial, ya a fines del 2008 se calcula que en el mundo había 4.000 millones de celulares (el $61 \%$ de la población mundial). Analfabetos, favelados descalzos, políticos y periodistas acceden a la telefonía inalámbrica para difundir sus mensajes, para convocar o denunciar.

La Sociedad de la comunicación se ha transformado en un hecho. Si en la Unión Soviética de Andropov -en los años setenta- se prohibieron las fotocopias, hoy en día nadie puede prohibir la telefonía móvil y los consiguientes mensajes de texto. En China existen los cargadores públicos de teléfono aún en lugares donde todavía no ha llegado la electricidad. En los Estados Unidos, ya en el año 2004, 32 millones de norteamericanos afirmaron obtener información de los diarios de Internet, y los lectores de 
blogs aumentaron en un 58\% en solo 6 meses. El blog es un diario personal que se escribe en Internet, donde no se busca dar específicamente información sino opinión personal, que los lectores buscan, comparan, comparten o critican. Paralelamente, muchos programas de televisión por cable comparten una tendencia que en el mundo anglosajón se llama periodismo de afirmación.

Con el crecimiento de Internet como plataforma abierta al público ${ }^{1}$, el periodismo de opinión (un anatema para el periodismo clásico) crece en forma exponencial, así como decrecen paulatinamente los lectores de periódicos, hasta el punto que ya no son pocos los que temen por su desaparición (al menos en su forma tradicional, ya que la prensa se ha visto obligada a desarrollar ediciones digitales). Los miedos y las fantasías que suscitó en especialistas, educadores y políticos el uso manipulativo de los medios, y los riesgos de tender hacia la pasividad frente a la pantalla de la televisión, se diluyen ante el nuevo escenario social y mediático. Los medios cubren desde el pequeño living familiar, pasando por el Estado, hasta los escenarios mundiales. Desde el fondo de mi casa hasta la cabina de los astronautas.

La respuesta al desafío de las transformaciones cuantitativas y cualitativas que traen los nuevos escenarios de la Cultura Tecnológica, ha sido la búsqueda de la articulación y la reintegración de todos los medios en complejos sistemas mutuamente interdependientes y en red. Redes más abiertas o más cerradas, pero que siempre deben permanecer alerta a todo lo que sucede, a riesgo de perder la exclusividad y su público, así como brindar canales de acceso y participación (o seudoparticipación) abierta al público.

Para pensar una modelización de este proceso que lo entienda en su complejidad y sin reduccionismos -por sobre todo tecnológicos-, tenemos al menos cuatro factores en juego que son sobredeterminantes en este nuevo escenario: la evolución de las tecnologías, la veloz disminución de

1 Hay que aclarar bien la diferencia entre la noción de web y la de Internet como una plataforma tecnológica -equivalente a una infraestructura de construcción y circulación de información y de productos virtuales y digitales, hasta el punto de que se está produciendo una auténtica infraestructura de Internet que recibe el nombre de Internet de los objetos-. Muchos confunden Internet con la web, el medio de producción con un "producto" que también se creyó universal, democrático y abierto, sin embargo la web está siendo apropiada por empresas que crean y explotan productos virtuales en la forma de nichos para el mercado (ver Anderson, 2010).

Mediaciones Sociales, № 8, I semestre 2011, pp. 21-43. ISSN electrónico: 1989-0494. DOI: 10.5209/rev_MESO.2011.n8.2 
los costos de producción, el acceso creciente a los usos sociales que permiten estas tecnologías, y por último los cambios en las demandas sociales. Dos factores son tecnológicos, uno es económico y el otro es social.

La multiplicación de las tecnologías de los medios, la miniaturización, y la accesibilidad económica aseguran la creación y la penetración de mercados hasta hace pocos años atrás reservados al Primer Mundo y a los sectores de mayor poder adquisitivo. Realmente debemos admitir que estos medios conforman la base de una infraestructura informacional que permite por primera vez pensar en la posibilidad de su uso democrático y alternativo a los medios dominantes. Si se me permite una metáfora marxista, prefiero pensar las posibilidades que abre este desarrollo tecnológico en términos de nuevas fuerzas productivas, como la infraestructura de una inminente Sociedad de la Información (una infraestructura hipertecnológica sobre cuyas bases se informan los dispositivos y las nuevas estructuras de producción y circulación capitalista). Por otro lado, pienso un modelo de sociedad utópica idealizada como una superestructura comunicacional, una Sociedad de la Comunicación abierta y democrática, con libre acceso a los conocimientos, a las opiniones y a las críticas.

Hay una consecuencia central en el pasaje de la sociedad industrial clásica a la sociedad de la infocomunicación -no deja de ser chocante considerar que la revolución industrial ha pasado en solamente dos siglos de ser el motor de las transformaciones hacia la modernidad, para tender a nuevas formas de conservatismo (aunque todavía dependiente de la producción física y el consumo de recursos naturales)-. Esta situación tiene profundas implicancias no solamente materiales sino también teóricas y epistemológicas. La tradición intelectual nos ha marcado con la impronta de pensar las estructuras y los procesos sociales y económicos desde la perspectiva de sus condiciones de producción. Una forma de determinación lineal y por etapas: producción, circulación y consumo. Las tecnologías -y los procesos de digitalización en primer término- han quebrado los parámetros de tiempo y espacio, introduciendo el pasado y el futuro en las ecuaciones de un presente continuo. El cálculo de probabilidades, el azar y la incertidumbre han entrado a formar parte de los planes de producción económica a una escala sin precedentes. La velocidad de la circulación de la información condiciona a los procesos de producción (un ejemplo de esto es el just in time). 
El acceso a los procesos, los dispositivos y las estructuras sobre las cuales se produce la circulación de bienes y de la información ha pasado a ser un recurso absolutamente estratégico. Los flujos del capital financiero constituyen en este sentido un ejemplo central. El modelo de la sociedad de la información presupone el crecimiento exponencial de los flujos inmateriales, y la dependencia creciente de ellos para asegurar la supervivencia de la sociedad real (por ej. cuando se produce un apagón de energía eléctrica, no es por falta del recurso físico, -lo que se puede prever-, sino de una falla en los sistemas de regulación y control de maquinarias y procesos).

Aún se nos hace difícil pensar los procesos productivos en términos de circulación, aunque sabemos que es en la propia circulación que el trabajo inmaterial de hombres y máquinas se va produciendo, y al mismo tiempo reproduciendo de este modo todo tipo de valores (económicos, políticos o culturales). No sabemos aún qué implicancias tendrán estas transformaciones infraestructurales en la sociedad, la política y la cultura. Sabemos que poseer información es tener poder, y nunca en la historia existieron tantas posibilidades y recursos de información-poder. Pero tampoco jamás en la historia el valor de la información se hallaba tan determinada por la fugacidad del tiempo, o más bien por la duración decreciente del valor de una información. Como no todo el mundo puede o está interesado en correr detrás de la información, inevitablemente se generan asimetrías a todo nivel. Esto se ve muy claramente en el mundo académico y la investigación científica, en la competencia económica, y en la "brecha digital" (the digital divide) entre países y sectores sociales.

\section{ENTRE SIGLOS}

A mediados del siglo veinte, la radio a transistor alimentó las expectativas de promover programas de desarrollo y modernización rural promovidas por la Escuela de Comunicación y Desarrollo. A comienzos del siglo XXI es Internet, la telefonía celular integrada y la convergencia digital -entre otras tendencias y tecnologías- las que representan las bases promisorias para generar condiciones para una sociedad de la comunicación más democrática y articulada a través de dispositivos de circulación social productiva. Cada ciudadano podría -al menos en teoría- constituirse en un productor-consumidor y en un militante público en circunstancias apropiadas. Pero debemos aclarar las limitaciones que estas innovaciones difícilmente puedan superar.

Mediaciones Sociales, № 8, I semestre 2011, pp. 21-43. ISSN electrónico: 1989-0494. DOI: 10.5209/rev_MESO.2011.n8.2 
El presente escenario guarda ciertas reminiscencias con las formas anarquistas en su rechazo a los condicionamientos y rigideces de las estructuras organizadas. Por otro lado, también presenta asociaciones con un individualismo activo que no choca en absoluto con el ideario liberal clásico. Los individuos se reúnen espontáneamente - o bien convocados para conformar una multitud ${ }^{2}$ (figura teórica cara a nuevos planteos de análisis político). Una multitud se reúne con fines precisos para "construir un acontecimiento", el que puede encuadrarse tanto desde un campo artístico (los happenings sesentistas) como uno político (la protesta de las cacerolas). El espontaneísmo construye el acontecimiento, emerge y se expresa en acciones y manifestaciones de todo tipo. Pero no construye -ni busca construir- organización, permanencia, compromisos fuertes y estables. El marginado social o el excluido, conformando un sector social creciente y ya estructural en la mayor parte del tercer mundo, pueden engrosar las filas de una multitud en una manifestación, pero no representan mas que un convidado casual y momentáneo que no modifica en nada sus condiciones objetivas de existencia. El paradigma tradicional de la organización social, con sus valores, compromisos e identidades fuertes, sigue siendo el dispositivo social mas adecuado para ejercer presión, expresar las injusticias y construir demandas dentro de un sistema social. Y tampoco el sistema social deja de estructurarse de acuerdo a reglas de poder, de propiedad, de distribución desigual de los recursos.

Un acontecimiento tiene todas las características de la comunicación: es un emergente expresivo de condiciones y situaciones, y puede revelarse a través de acciones directas, o por operaciones mediáticas con un comienzo y un fin; requiere de actores sociales en situaciones y contextos específicos. Pero cuando termina, es como la representación teatral, cada uno vuelve a su realidad: los actores bajan del escenario, el público que se ha regocijado, sufrido o conmovido, aplaude. Baja el telón y todos vuelven a sus casas.

Las tecnologías de información y comunicación tienen la virtud de generar nuevos espacios y tiempos, nuevos dispositivos, pero también

2 Rheingold habla de "multitudes inteligentes", como grupos de personas que emprenden movilizaciones colectivas gracias a que un nuevo medio de comunicación, posibilitando otros modos de organización entre personas que hasta entonces no podían coordinar tales movimientos.

Mediaciones Sociales, № 8, I semestre 2011, pp. 21-43. ISSN electrónico: 1989-0494. DOI: 10.5209/rev_MESO.2011.n8.2 
nuevas formaciones infraestructurales. Las acciones mediatizadas seguramente puedan llegar a establecer en un futuro cercano nuevas prácticas que terminen tejiendo las nuevas ecologías en red de la sociedad de la información. Su especificidad y dinámica corresponde a las lógicas de la circulación más que a las de la producción tal como se lo ha entendido en la sociedad industrial. Así como le ha llevado siglos a la era industrial superar la era feudal, aún no podemos saber cuanto le llevará a esta móvil y "reflexiva" sociedad conformar nuevas relaciones de produccióncirculación. No sabemos si el paradigma de esta nueva sociedad (¿de la información, del conocimiento, o de la comunicación?) promoverá más desigualdad y más concentración de poder, o si logrará distribuir más equitativamente los recursos que aseguren un acceso más igualitario a mejores condiciones de vida compartidas por toda la sociedad.

Mientras tanto, en nuestra "modernidad líquida” -al decir de Bauman-, y después del fracaso de las estructuras burocráticas y la planificación centralizadas, los movimientos sociales parecen hallarse ante la necesidad de desarrollar estrategias duales, articuladas sobre acciones físicas y a la vez comunicacionales. Entre la organización rígida o la flexible; entre la "guerra de posiciones" y el acontecimiento; entre un monólogo repetitivo o el diálogo abierto. Esperemos que las TIC -más allá de los intereses económicos y geoestratégicos- puedan seguir abriendo los canales de diálogo, aunque sea en un campo de batalla simbólico minado por un sinnúmero de prejuicios e intereses particulares.

\section{El SUJETO EN MOVIMIENTO: CELULARES, CONVERGENCIAS E HI- PERMEDIATIZACIÓN}

En las últimas décadas del siglo XX las TIC demostraron la capacidad de convergencia que les permite expandir exponencialmente no solo múltiples usos diferentes, sino la posibilidad de creación y acceso universal a redes de información y de comunicación. Ya en la primera década del siglo XXI el celular personal y el desarrollo de aplicativos entre redes y dispositivos de infocomunicación (presentando un cuadro más asimilable a una Sociedad de la Comunicación que de la Información) reinstala al individuo como un agente activo de convergencia entre múltiples sistemas de comunicación. Si el modelo de ser humano en la cultura letrada de la Modernidad era el sujeto lector reflexivo, en la presente modernidad tardía

Mediaciones Sociales, № 8, I semestre 2011, pp. 21-43. ISSN electrónico: 1989-0494. DOI: 10.5209/rev_MESO.2011.n8.2 
(¿postmodernidad?) el nuevo modelo vigente -aunque utópico- es el sujeto móvil e itinerante de la nueva aldea globalizada (y desterritorializada) ${ }^{3}$.

Vale la pena analizar el contexto y las condiciones históricas que fueron configurando el nacimiento de este sujeto móvil de la (pos)modernidad. Ese privilegio había sido ya insinuado en el Renacimiento con el comienzo de los viajes de los navegantes, y en la pintura a través de la toma de conciencia del pintor como observador y el descubrimiento de la representación como perspectiva recreadora del espacio visual. Tampoco es casual que en la filosofía Descartes haya establecido ontológicamente a la conciencia individual y al pensamiento racional como únicas fuentes de verdad ("pienso luego existo"). Ya en el siglo XIX los individuos comienzan a movilizarse en los trenes y las geografías del espacio moderno que se pueblan de vías ferroviarias y canales. En el mundo de la representación visual, los impresionistas ven la realidad física como impresiones subjetivas de luz y color, instalando así al individuo como un observador capaz de medir y recrear la realidad de acuerdo a su propia perspectiva y a un punto de vista personal. A comienzos del siglo XIX, el Romanticismo instala objetivamente la historia y el tiempo pasado, el surgimiento de la prensa de masas recrea e instala la conciencia del presente, la fotografía reproduce la realidad física (objetiva), la novela y las artes del siglo XIX instalan finalmente la figura de la subjetividad creativa, y ya a fines de siglo el psicoanálisis introduce la figura de la duda, la sospecha y el análisis.

La Modernidad ha generado más que el conjunto de saberes expresados en las bibliotecas y la academia, ha instituido sobre todo la creación de la figura del observador individual, de una conciencia subjetiva separada epistémicamente del mundo real de los objetos. Ya en el siglo XX los medios de comunicación masivos multiplicaron y recrearon diferentes representaciones de la realidad, reinstalando al individuo como un observador mediatizado, como sujeto y objeto de nuevas experiencias perceptivas masivas. Los medios masivos y la publicidad generaron las representaciones sociales y las motivaciones adecuadas a prácticas de consumo acordes con la creación de mercados para las nuevas industrias (recordemos a Ford y el culto al automóvil popular).

\footnotetext{
¿Por qué asombrarse entonces del rechazo a la lectura que muestran los jóvenes criados en la era audiovisual?
}

Mediaciones Sociales, № 8, I semestre 2011, pp. 21-43. ISSN electrónico: 1989-0494. DOI: 10.5209/rev_MESO.2011.n8.2 
Con las innovaciones tecnológicas acelerando día a día la creación y adopción de nuevos dispositivos a un mercado global, finalmente las TIC se presentan como las responsables de proveer mecanismos de convergencia necesarios para articular una multiplicidad explosiva de nuevas fuentes de producción y circulación de información, de mensajes y programas. Se multiplican ad infinitum las representaciones virtuales a través de las experiencias multimediáticas, recreando entornos y contextos diferentes teniendo al individuo como eje central de la experiencia perceptiva. El fenómeno de la convergencia deja de ser solamente técnico para tornarse en múltiples procesos de convergencia social, cultural y política.

En una primera etapa, el cine, la radio y la televisión en tanto dispositivos técnicos, aún se presentaban en la forma de una fuente fija e indispensable, de la cual el individuo dependía en forma prácticamente absoluta para sus necesidades, podemos decir que el hombre debía ir hacia el medio, $\mathrm{y}$ adaptarse a las condiciones de funcionamiento del dispositivo (radio, televisor, teléfono fijo, etc.). No creo exagerar al afirmar que la mayor innovación sociotécnica de los últimos años se halla en la telefonía celular, ya que disminuye la dependencia de una fuente fija y permite la movilidad del usuario, asegurando la convergencia entre diferentes clases de experiencias, usos y situaciones de la vida en contextos de tiempo real. El celular hace posible una convergencia social y pública tanto para los individuos como las organizaciones y la cultura en general. Una verdadera convergencia de funciones con infinita cantidad de información y contenidos referenciales y una convergencia comunicacional interreferencial para las relaciones sociales (creación de vínculos entre individuos y experiencias organizativas, aunque estén situados en parámetros de tiempo y espacio diferentes).

Esto tendrá consecuencias institucionales sobre los modos en que las sociedades vivirán sus experiencias políticas -en especial para las incipientes prácticas de democracia participativa y la gradual erosión de las formas de representación política tradicional-. Otra consecuencia inevitable consiste en la profundización y la expansión de las prácticas laborales de la economía de la información, el cuentapropismo, el teletrabajo, etc. La virtualidad digital permite la creación de múltiples mundos de la vida mediatizados también desde una perspectiva 'autorreferencial'. Esta autorreferencialidad en los medios y en la web se revela en la inundación de programas, canales y escenarios mediatizados que tienen como leitmotiv la vida privada y la subjetividad, (una conciencia posmoderna que guarda una 
relación de rechazo y rebeldía con la conciencia racional de Descartes, y cierto descuido deliberado con criterios de verdad y objetividad). Su única preocupación es la expresión y la exhibición personal, la búsqueda del Otro anónimo como observador, la vivencia del presente, el momento, el aquí y ahora. Y funciona en base a las expresiones del individuo en perpetuo movimiento, sin anclajes en un antes o un después.

El actor de la nueva cibercultura no piensa sobre la información, sino que procesa información. El pensar ya no es algo separado de la acción, sino una función más de la propia acción. El celular superará a las computadoras porque reúne imagen con lenguaje, pero también percepción con acción. Es una nueva clase de experiencia de convergencia mediatizadat. Instala al sujeto como constructor activo de significados. Un sujeto hipermediatizado, capaz de reunir objetiva y subjetivamente tanto su vida privada como pública, todo a través de actividades sociales y económicas (más aún, se diluye la separación entre unas y otras). Esto nos lleva a la necesidad de una redefinición sobre lo que se considera trabajo en este contexto, y a la cuestión de la convergencia entre actividades separadas que puedan ser rearticuladas a una actividad social compartida y a la producción de valores (tanto para el mercado como para actividades políticas, sociales y culturales). Este será el sujeto del nuevo capitalismo cognitivo o informacional y las nuevas formas de trabajo inmaterial capaces de generar valor por medio de la transformación de objetos virtuales y objetos de información en commodities. Pero la hipermediatización no solamente tiende a transformar el mercado de trabajo (como en el caso del teletrabajador), sino también implica el cambio de las prácticas en los escenarios políticos, generando nuevas formas de acción colectiva, eventos públicos y formas de organización espontánea de grupos y masas en colectivos sociales.

Tomemos nuevamente el ejemplo de los eventos políticos de las manifestaciones de Madrid en el 2004 unos días antes de las elecciones y el caso de Irán después de las elecciones del 2009, donde miles de ciudadanos sa-

4 De acuerdo a un relevamiento de la Queensland University of Technology (QUT) de Australia, el $22 \%$ de los australianos de entre 6 y 9 años ya tienen un celular propio. El porcentaje alcanza el 60 entre los de 10 a 14 años, mientras que trepa hasta el $84 \%$ entre los de 15 a 18 años. (Diario Clarín, 2/3/2010). "Llama la atención la velocidad de ascenso que consiguió el celular en un corto plazo. Las pantallas generaron nuevas formas de sociabilidad juvenil. Y el celular cumple con esas funciones: chatear, mandar mensajes, navegar, escuchar música, ingresar a las redes sociales. Esto lo hace sin diferenciación, porque atraviesa todos los sectores sociales. En cambio la computadora tiene mayor valoración donde hay conectividad" (R. Morduchowicz, Diario Clarín, 2/3/2010).

Mediaciones Sociales, № 8, I semestre 2011, pp. 21-43. ISSN electrónico: 1989-0494. DOI: 10.5209/rev_MESO.2011.n8.2 
lieron a repudiar como fraudulentos los resultados de las elecciones. El caso de Irán es particularmente interesante ya que esta vez la protesta sucede en un país musulmán sujeto a un régimen teocrático. La religión islámica, al prohibir la representación de la imagen divina, e inhibir o al menos restringir la reproducción de la imagen humana (a imagen de dios) eliminó la perspectiva individual de expresión del sujetocentrismo propio de la Modernidad occidental. La tradición religiosa eliminó culturalmente la posibilidad de desarrollar una perspectiva individual distanciada y secular del cuerpo y de los seres humanos -y obviamente también la perspectiva femenina- en las representaciones pictóricas y culturales ${ }^{5}$. Si los talibanes prohibieron la televisión (que reproduce infinita cantidad de imágenes del cuerpo humano en diferentes gestos y posiciones, comprometiendo así la prohibición islámica), ya el teléfono celular transformado en un instrumento de libre expresión y autorreferencialidad para cualquier ciudadano individual, puede llegar a ser considerado prácticamente un instrumento subversivo para un régimen teocrático, al potenciar la capacidad de expresión y autorreferencia de los sujetos.

La penetración irrestricta de dispositivos de información y de comunicación en todas las actividades humanas tiende a generar procesos de convergencia crecientes en los mercados de consumo ${ }^{6}$, en las organizaciones y las manifestaciones políticas, en los eventos culturales y en los procesos simbólicos e imaginarios de nuestras mentes. Así se hacen entendibles las fantasías depositadas en los medios de información y comunicación, ya que se hallan en una posición estratégica, tanto para promover acciones de violencia y conflicto como de solidaridad social; de profundización del control social tanto como de su pérdida, de instrumento de organización como de des-organización social.

5 Esto explica el extraordinario desarrollo de la geometría como ciencia y como arte islámico. Y vale la pena comentar también un maravilloso cuento de Borges en el que Averroes, que busca en vano traducir de Aristóteles los términos "tragedia" y "comedia" (pues esas formas de arte no existían en la cultura musulmana), escucha hablar de un extraño suceso al que había asistido un visitante en China, donde personas enmascaradas y vestidas como personajes de otros tiempos, actuaban en un escenario de modo incomprensible.

6 "La evolución natural de las redes celulares. Hoy, cuando la mayoría de los usuarios de telefonía celular están comenzando a aprovechar las ventajas de las modernas redes de tercera generación ( $3 \mathrm{G})$, las empresas de telefonía móvil y los fabricantes de tecnología ya están pensando -y trabajando- en el próximo paso, las redes $4 \mathrm{G}$, que permitirán que con los celulares pueda hacerse, sin limitaciones, todo lo que hoy puede hacerse con una computadora de escritorio, incluido hacer videollamadas, entretenerse con juegos interactivos en tiempo real, y mirar videos de la Web" (Clarín, nota del 15/12/2009).

Mediaciones Sociales, № 8, I semestre 2011, pp. 21-43. ISSN electrónico: 1989-0494. DOI: 10.5209/rev_MESO.2011.n8.2 
La hipermediatización es un desafío central para las sociedades, ya que se halla en el cruce de innumerables prácticas y cuestiones económicas, políticas, culturales y simbólicas. La sociedad tecnológica actual está soportada por una compleja articulación entre una infraestructura informacional y una superestructura semiótica-comunicacional (como procesos de construcción de sentido y valores de intercambio social y como una de las formas específicas de interreferenciación y creación de procesos y contenidos interactivos). De modo que la idea de una sociedad de la información es sobre todo una forma de reduccionismo económico e ingenieril, ya que realmente estamos inmersos en redes de relaciones que corresponden mas bien a un entorno comunicacional convergente, construido a través de interacciones, flujos de información, dispositivos mediáticos y redes interconectadas. Una paradoja de esta parafernalia de dispositivos tecnológicos estriba en que la gente tiene la sensación de estar conectada (connectedness) aunque éstas conexiones no generan subjetivamente una real y significativa comunicación en medio del océano de mensajes ${ }^{7}$. La paradoja de una conexión permanente y al mismo tiempo la sensación de aislación individual parecen profundizarse (la comunicación social se está tornando crecientemente autorreferencial, personal y subjetiva, con lo que los cuadros de depresión que invaden los consultorios de salud mental merecen ser cuidadosamente investigados tomando en consideración posibles relaciones con la hiperconectividad de los individuos o la hipermediatización de la sociedad).

\footnotetext{
7 Una investigación realizada en el 2009 en los EEUU por Pear Analytic reveló que un 40\% de los mensajes de Twitter son considerados 'inútiles'. Entre los textos considerados 'útiles' $37,55 \%$ son conversaciones entre usuarios, $8,7 \%$ son reproducciones de otros microblogs, $5,85 \%$ son textos de autopromoción, $3,75 \%$ son spam y solo $3,6 \%$ son noticias (Zero Hora, POA, Brazil, 11/12/2009).

Un estudio realizado por la Universidad de California revela que los norteamericanos consumen un promedio de 34 gigabytes y 11,8 horas de información por día, aunque no procesen las 100.000 palabras que la 'soportan'. En término medio, los norteamericanos consumieron 1,3 trillones de horas absorbiendo información en el 2008. La cantidad de bytes consumidos entre 1980 y 2008 aumentó un $6 \%$ anual, y gracias a las computadoras, un tercio de las palabras y un $50 \%$ de los bytes son recibidos interactivamente. La lectura, que cayó inicialmente debido a la Tv, se triplicó entre 1980 y el 2008, porque la lectura es la forma preferida de absorber contenidos en Internet (O Sul, de P. Alegre, 11/12/2009).
}

Mediaciones Sociales, № 8, I semestre 2011, pp. 21-43. ISSN electrónico: 1989-0494. DOI: 10.5209/rev_MESO.2011.n8.2 


\section{HiPERMEDIATIZACIÓN SOCIAL: ALGUNAS TENDENCIAS ESPECÍFI- CAS ASOCIADAS A LAS TIC}

1. Las TIC tienden hoy a una re-localización (por ej. los aplicativos de geolocalización). Se crean y delimitan lugares, tanto espacios como tiempos que pasan de la realidad virtual a la real (lo virtual se real-iza, o como sintetiza el investigador brasileño A. Lemos: se va de una etapa de upload a una de download). Los dispositivos de información unidos a dispositivos de control y manipulación a distancia, si bien crean espacios y lugares, paradójicamente eliminan la noción de distancia, tiempo y espacio.

2. Los tradicionales mundos de la vida concebidos por Husserl y la fenomenología tienden a recrear nuevas modalidades de trabajo: el propio ocio se puede transformar en actividades de reproducción económica a través de procesos biológicos, tecnológicos, sociales y simbólicos realizados en la Red (todo a un mismo tiempo, planteando así las dificultades para construir teorías adecuadas sobre estas transformaciones radicales, y replanteando críticamente la noción de ideología, así como también se hace imperativo entender las nuevas relaciones mutuas entre capital, trabajo y mundo de la vida en la economía de la información global).

3. Los procesos de producción de valor tienden a subsumirse y reproducirse a través de los propios procesos de circulación (como los 'derivativos' de la economía financiera y sus consecuencias de falsa valorización y las burbujas especulativas). Esta tendencia -consecuencia directa de la convergencia de las redes y el connectedness- tiende a una transformación paulatina de los productos en servicios y valor (con el consiguiente aumento del PBI global). El público pasa a comprar servicios (experiencias) mas que productos físicos. La mediatización social se confunde con la digitalización.

4. Crisis de pasaje de los procesos de representación (tanto del mundo físico como social, de sectores y de clases sociales) a los procesos de presentificación. Las imágenes pasan a formar parte de diferentes prácticas sociales y de acontecimientos en acción. El tiempo del observador se diluye en el tiempo del actor. De una audiencia pasiva a una participativa. En el mundo de la política, las instituciones y el Estado, se dificulta la participación social porque los ciudadanos -así como la mayoría de las instituciones- tienden a mantener el viejo paradigma de una audiencia pasiva, la 
burocracia formal, los tiempos rituales y el red tape. Esperemos que el uso de la TIC pueda ir modificando este panorama.

5. Se profundizan y aceleran las transformaciones impuestas por todas las formas de convergencia: tecnológica (en especial digital), política, social y cultural.

6. Idas y vueltas en espiral entre lo concreto real a lo virtual, y de éste último volviendo a lo real modificándolo, para luego volver nuevamente a un mundo virtual (es imperativo no dejar dudas en cuanto a que lo virtual es también real). Este proceso en espiral entre lo real y lo virtual es posible por:

7. El pasaje de los procesos de interpretación intelectual al mundo de los códigos y los programas de lenguajes operacionales. En otras palabras, por la suplantación de los lenguajes naturales y la comunicación humana por dispositivos de mediación desarrollados por la ingeniería de la información.

8. La profundización creciente de la apropiación de los mundos de la vida, de la cultura y la subjetividad por parte del mercado, asociado a las corporaciones y los dispositivos de mediatización social (proceso que Bauman -parafraseando a Marx- denomina sagazmente como fetichismo de la subjetividad, tal como podemos observar en la multiplicación de reality shows, de exhibiciones de la intimidad, y una autorreferencia al ego y al mundo del deseo en forma compulsiva).

9. Tal como señalé anteriormente respecto a la relación entre el medio y el usuario, la tendencia a la miniaturización y la convergencia redefinen el papel de las tecnologías en el sentido de acompañar cada vez mas situaciones, experiencias y usos adaptados a las necesidades de movilidad, autonomía y multiuso de los dispositivos a las necesidades de los usuarios en la vida cotidiana (en el trabajo, el ocio, el estudio, la participación política y cultural). La mayor autonomía de movimiento y acceso a actividades privadas o públicas, tiende a profundizar las tendencias de individuación y participación social mediatizada, con el consiguiente riesgo de suplantación de los lazos sociales físicos por la participación en redes virtuales.

10. Si bien las ligaciones entre las tecnologías, la creatividad y las expresiones artísticas tienden a crecer y profundizarse, en el ámbito de la

Mediaciones Sociales, № 8, I semestre 2011, pp. 21-43. ISSN electrónico: 1989-0494. DOI: 10.5209/rev_MESO.2011.n8.2 
educación y la producción mediática se va delineando con mas claridad la necesidad de desarrollar en forma específica los contenidos, la innovación y la creatividad como ámbitos de producción y creación de valor diferenciados de los dispositivos hard (por ej. el concepto de industrias culturales tiende a ser suplantado por el de industrias de contenido o creativas. El sentido trasciende al signo, y la imaginación trasciende a la imagen).

11. La telefonía celular nace como un dispositivo de comunicación, pero los desarrollos de la biotecnología en asociación con la nanotecnología abre infinitas posibilidades de convergencia con nuevos dispositivos de conectividad con las TIC y las redes, y augura un horizonte de innovaciones revolucionarias en las relaciones entre el cerebro, la mente y los dispositivos de infocomunicación como la telefonía móvil.

12. La producción colaborativa de contenidos digitales tenderá a crecer en forma exponencial, y esto tendrá consecuencias fundamentales para el mundo del trabajo, la educación, la producción y difusión de conocimiento e información (tómese en cuenta el crecimiento del denominado periodismo 3.0, donde los lectores aportan contenidos e información, participando -aún modestamente- de la producción mediática).

13. La evolución de la tecnología de los dispositivos mediáticos ha producido un salto cualitativo para la ecología mental, perceptual y táctil de la humanidad. Se puede hacer una historia de los medios a partir de sus soportes materiales: del muro de la caverna al papel, pasando por la pantalla fija, la del computador a las pantallas móviles, y a las aún algo utópicas 'pantallas mentales'. El Knowledge Media Design Institute (KMDI) de la Universidad de Toronto desarrolla a partir de 1997 un programa estratégico de aplicaciones sobre todo orientadas a la educación y al diseño a través de medios, considerados ya como Medios de Conocimiento (Knowledge Media) (Baecker, 1997).

14. Un enorme impacto irreversible se presenta ya a nuestras instituciones educativas y a las modalidades que se imprimen aceleradamente sobre los procesos de formación permanente. La teleeducación y la transnacionalización de la educación superior abren enormes posibilidades para la integración y la cooperación regional e internacional, sin embargo la Sociedad del Conocimiento - como todo conocimiento - no se constituye solo como un proceso autónomo e ideal, sino que viene acompañado también por diferentes instancias de poder, de hegemonía e influencia y de 
refinadas modalidades de control sobre las identidades y las formas culturales mas débiles.

15. Rápidamente se van generalizando las aplicaciones de lo que se ha dado en llamar el Internet de las cosas (viviendas y ropas inteligentes, sistemas de supervisión, control y de gestión, etc.). Podemos decir que estamos pasando de la etapa metafísica del 'todo esta conectado con todo' dentro del mundo físico, a una etapa 'superior' donde todo tiende a estar conectado entre sí por medio de la información digitalizada. Y el celebrado 'efecto mariposa' se ha concretado por medio de dispositivos de interconexión, circulación y respuesta instantánea donde el sigilo y los secretos son cada día mas difíciles de mantener, y los efectos finales prácticamente impredecibles.

Esta breve mención de procesos y transformaciones del mundo realvirtual ayuda a comprender de que maneras nos hallamos viviendo en realidades, entornos y mundos de la vida donde se modifican los espacios y los tiempos en la economía, en la política y en nuestras vidas cotidianas. ¿Cómo haremos para mantener una evaluación crítica sobre las realidades que analizamos en nuestros proyectos de investigación? ¿Cómo contemplar la necesidad de cambios y adaptaciones entre las 3 dimensiones de nuestros proyectos de investigación: la realidad objeto de investigación, las teorías y proposiciones sobre esas realidades, y por último, los métodos que empleamos para abordar la triple y compleja relación entre el saber, el hacer y el poder?

Como las tendencias mencionadas mas arriba pueden dejar al lector una impresión veladamente triunfalista sobre la evolución de las tecnologías y la mediatización social, creo interesante agregar un par de observaciones desde una perspectiva prudente y crítica como la del investigador argentino Diego Levis:

"los mundos virtuales son 'no lugares', pero nuestros cuerpos no pueden ser 'no cuerpos'. Este conflicto entre no lugares y cuerpos verdaderos es el centro gravitatorio sobre el cual gira la reflexión sobre la inmaterialidad digital, entendiendo como tal los espacios simbólicos generados por un sistema informático. El cuerpo no es un símbolo, y mucho menos un objeto”.

Y prosigue: 
"La palabra mágica para la cibercultura...es 'interactividad'. Interactividad que en las tecnologías informáticas tiende a la neutralización del Otro. Cada interacción se reduce a un 'diálogo' sin fin con la máquina, en el que el otro es virtualmente uno mismo (la alteridad es confiscada por la máquina)” ( Levis, 2009: 124).

Considero que estas observaciones manifiestan la necesidad que muchos percibimos de mantener la prudencia, y profundizar la revisión de ciertas proposiciones tales como la noción de interacción mediada por ordenador', en especial tomando en consideración los argumentos presentados sobre el proceso de comunicación humana desde la noción de interreferenciación.

Para terminar, algunas preguntas clave: ¿cómo y hasta qué punto estas transformaciones modifican las formas de organización y de producción en el capitalismo como sistema, y los instrumentos teóricos que empleamos para entender y operar en sus condiciones y leyes de funcionamiento ? ¿Cómo entender este tardocapitalismo informacional y cognitivo? ¿Cómo se modifican las relaciones de producción que subsisten en las economías más tradicionales ? ¿Cómo impactan sobre la estructura y las dinámicas de los procesos sociales y sobre las concepciones y las prácticas políticas?

\section{BibLIOGRAFÍA}

AA. VV. (1999): Le Dispositif: entre usage et concept. Hermés 25: Cognition, Communication, Politique. París: Ed. CNRS.

Anderson, C. (2010): “The web is dead", Wired, septiembre de 2010. Disponible en: http://www.wired.com/magazine/2010/08/ff_webrip/all/1 Consultado el 9 de junio de 2011.

BAECKER, Ronald (1997): “The Web of Knowledge Media Design Highlights”, 23 January 1997, OISE Auditorium Toronto, Canada.

Bauman, Zygmunt (2004): Modernidad Líquida. Buenos Aires: Fondo de Cultura Económica.

Charaudeau, P. (1997): Le discours d'information médiatique. La construction du miroir social. París: Nathan.

Mediaciones Sociales, № 8, I semestre 2011, pp. 21-43. ISSN electrónico: 1989-0494.

DOI: 10.5209/rev_MESO.2011.n8.2 
Corsani, A.; Lazzarato, N. (1996): Le bassin de travail immatériel (BTI) dans la métropole parisienne. París: Ed. L’Harmattan, Logiques Sociales.

Chang, Briankle (1996): Deconstructing Communication. Minnesota: University of Minnesota Press.

DownING, John D. H. (2002): Mídia radical: rebeldia nas comunicações e movimentos sociais. São Paulo: Senac.

GorZ, A. (2005): O Imaterial, Conhecimento, valor e Capital. Sao Paulo: Annablume.

Kerszberg, P. (2001): "Phénoménologie de léxperience sonore”, en SouZA, T. \& Oliveira (orgs.): Fenomenología hoje. Existéncia, ser y sentido no alvorecer do século XXI. Porto Alegre: EDIPUCRS.

HINE, Christine. (2005): Virtual methods: issues in social research on the internet. New York: Berg.

JEnkins, H. (2006): Convergence Culture. New York: New York University.

Johnson, S. (2001): Emergence (The Connected lives of Ants, Brains, Cities and Software). New York: Scribner.

Lemos, A. (2002): Cibercultura. Tecnología e vida social na cultura contemporánea. Porto Alegre: Sulina.

Lemoigne, J. L. (1995): La modélisation des systèmes complexes. París: DUNOD.

LEvis, D. (2009): La pantalla ubicua. Buenos Aires: La Crujía (2a ed.).

Lotman, I. (1996): La semiosfera. Semiótica de la cultura y del texto. Madrid: Cátedra / Universidad de Valencia.

Lull, J. (1995): Media, communication, culture, a global approach. Nueva York: Columbia University Press.

MaNOVICH, L. (2006): El lenguaje de los nuevos medios de comunicación. La imagen en la era digital. Buenos Aires: Paidós.

MeluCCI, A. (2001): A invencao do presente: movimentos sociais nas sociedades complexas. Brasil: Vozes, Petrópolis.

MiÈGE, B. (2000): O pensamento comunicacional. Brasil: Vozes, Petrópolis. 
«El sujeto móvil de la aldea global. Tendencias en la sociedad mediatizada»

Recuero, R. (2009): Redes sociais na internet. Porto Alegre: Sulina.

RHEINGOLD, H. (2004): Multitudes inteligentes. Madrid: Gedisa.

Schnitman, D. F. (1994): "Nuevos Paradigmas Cultura y Subjetividad", en Ponencias y diálogos del Encuentro Interdisciplinario Nuevos Paradigmas Cultura y Subjetividad. Buenos Aires: Paidós.

TACUSSEl PATRICK, A. (2002): "Sociología interpretativa”, Famecos, nº 18.

TURNER H. (2000): Rethorics of welfare. Oxford: Oxford University.

Vizer, Eduardo A. (1987): "The Challenges of developing a Technological Culture", conferencia pronunciada en el United Nations Department of Public Information, Nueva York. Trad. en Telos, nº 37, 1994.

Vizer, Eduardo A. (1994): “Desafíos ante la Globalización de la Comunicación”, en RAPAPORT, Mario (comp.): Globalización, Integración e Identidad Nacional. Buenos Aires: GEL.

Vizer, Eduardo A. (1994): "El modelo Actor-Observador y el desarrollo de una perspectiva comunicacional”, en Teorías Iberoamericanas de la Comunicación. México: Universidad de Guadalajara y ALAIC, pp. 363-393.

Vizer, Eduardo A. (2003): “Ciencias' de la Comunicación: ¿qué 'Cultura institucional y disciplinaria' estamos construyendo?”, Fronteiras, vol. 5.

Vizer, Eduardo A. (2004): “'Sociedad de la (in)formación o de la comunicación? Entre el condicionamiento y la libertad”, Signo y Pensamiento, vol. XXIII, ${ }^{\circ} 44$, pp. 41-52.

Vizer, Eduardo A. (2005): "Socioanálisis. Metodología de investigación, análisis diagnóstico e intervención social”, Redes.Com. Revista de Estudios para el Desarrollo Social de la Comunicación, $\mathrm{n}^{\circ}$ 2, pp.415-430.

VIZER, Eduardo A. (2006): La trama (in)visible de la vida social: comunicación, sentido y realidad. Buenos Aires: La Crujía (2 $2^{\mathrm{a}}$ ed.). Versión en portugués: Sulina, 2011.

Vizer, Eduardo A. (2007): "Hacia una ecología social y estratégica de la comunicación”, Paper a Coloquio Transfronteiras. Publ. Secret. de Ciencia y Téc., Facult. de C. Sociales, Universidad de Buenos Aires. 
Vizer, Eduardo A. (2007): "Procesos sociotécnicos y mediatización en la Cultura Tecnológica”, en Moraes, Denis (coord.): Sociedad mediatizada. Barcelona, Gedisa, pp. 39-69.

Vizer, Eduardo A. (2008): "Mediatização e (trans)subjetividade na Cultura Tecnológica. A dupla face da sociedade mediatizada”, en VV.AA.: Mediatizaçao e processos sociais na América Latina. São Paulo: Paulus, pp. 31-51.

VizER, Eduardo A. (2008): "Trans-formaciones sociales y relaciones sociotécnicas en la cultura tecnológica”, en BRITTOS, V. C. \& CABRAL, Adilson (orgs.): Economía Política da Comunicaçao. Interfases Brasileiras. Rio de Janeiro: E.papers, pp. 132-147.

VizER, Eduardo A. (2009): "Etapas de la cultura tecnológica y creación de valor", en Fagundes Hausen, D. \& Cruz Brittos, V. (orgs.): Economía Política, Comunicaçao e cultura. Porto Alegre: Pontificia Universidade Católica do R.G.S., pp.181201.

VizER, Eduardo A. (2009): "Social dimensions of communication; communicational dimensions of social processes. Some propositions on problematic research lines", Famecos, n⿳0 40, pp. 15-23.

Vizer, Eduardo A. (en prensa): Comunicación y Socioanálisis. Estrategias de investigación e intervención social. Buenos Aires: La Crujía.

Vizer, Eduardo A. et al. (2007): Mídia e movimentos sociais. Linguagens e coletivos em açao. Sao Paulo: Paulus. 


\section{PARA CITAR ESTE TRABAJO EN BIBLIOGRAFÍAS:}

VIZER, Eduardo Andrés (2011): "El sujeto móvil de la aldea global. Tendencias en la sociedad mediatizada", Mediaciones Sociales. Revista de Ciencias Sociales y de la Comunicación, $\mathrm{n}^{\mathrm{o}}$ 8, pp. 21-43. DOI: 10.5209/rev_MESO.2011.n8.2; http://dx.doi.org/10.5209/rev MESO.2011.n8.2

\section{${ }^{(*)}$ El autor}

Eduardo Andrés Vizer es doctorado en Sociología. Profesor invitado de la Universidad de la Integración Latinoamericana (Brasil). Profesor e investigador consulto del Instituto Gino Germani (Argentina). Fundador de la carrera de Ciencias de la Comunicación en la Universidad de Buenos Aires. Coordinador de Epistemología y Teoría del Conocimiento: Maestría en Estudios Sociales y Culturales, Universidad Nacional de La Pampa. Profesor visitante en universidades de Estados Unidos, Canadá y Europa. Evaluador de posgrados CONEAU, SECYT (Secretaría de Ciencia y Técnica). Evaluador del Communication Department de la University of Massachussets (UMASS-USA). Ex Fulbright Fellow, Internationes (Alemania), ICCS de Ottawa (Canadá). Su libro más importante es La trama (in)visible de la vida social: comunicación, sentido y realidad ( $2^{\mathrm{a}}$ ed. 2006; edición en portugués: Sulina, 2011). Tiene ocho libros publicados.

RECIBIDO: 2 de febrero de 2011.

ACEPTADO: 10 de mayo de 2011. 
